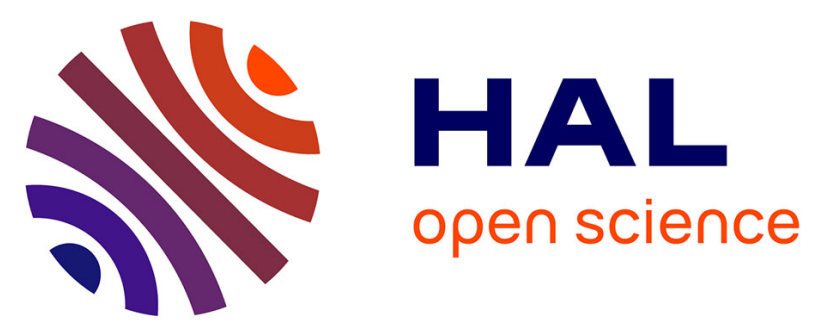

\title{
Roles of the metacognition and emotional systems in a categorization task for adults with moderate and severe learning disabilities
}

\author{
Suzanne Igier, Valérie Pennequin
}

\section{To cite this version:}

Suzanne Igier, Valérie Pennequin. Roles of the metacognition and emotional systems in a categorization task for adults with moderate and severe learning disabilities. International Journal of Developmental Disabilities, 2020, pp.1-9. 10.1080/20473869.2020.1759952 . hal-03133876

\author{
HAL Id: hal-03133876 \\ https://hal.science/hal-03133876
}

Submitted on 26 Oct 2021

HAL is a multi-disciplinary open access archive for the deposit and dissemination of scientific research documents, whether they are published or not. The documents may come from teaching and research institutions in France or abroad, or from public or private research centers.
L'archive ouverte pluridisciplinaire HAL, est destinée au dépôt et à la diffusion de documents scientifiques de niveau recherche, publiés ou non, émanant des établissements d'enseignement et de recherche français ou étrangers, des laboratoires publics ou privés. 
Suzanne Igier, ${ }^{1}$ Pennequin Valérie, ${ }^{1}$

${ }^{1}$ E.A 2114 Psychologie des Ages de la Vie, Université François Rabelais,

3 Rue des Tanneurs, 37041 Tours Cedex, France.

Corresponding author: suzanne.igier@etu.univ-tours.fr

vpennequin@univ-tours.fr

Phone number: 0247366600

\section{$\underline{\text { Acknowledgments }}$}

We would like to show our gratitude to the ADAPEI 41 (institutions supports to people with intellectual disabilities) and more specifically Mr Barragan for his permission to propose our experimentation in this association. We are also immensely grateful to all the participants

Research funding is academic, with no restrictions on access or publication of data. No financialconflicts of interest have been declared and finally, all authors have contributed to, seen, and approved of the manuscript and agree to the order of authors as listed on the title page. 


\section{Abstract}

This research aimed to evaluate the links between metacognitive experiences, emotional coping strategies and categorization in adults with severe and moderate intellectual disabilities. The participants consisted of 32 people between 23 and 70 years old and having severe and moderate intellectual disabilities were recruited in several institutions. Their metacognition and their coping strategies were assessed using questionnaires before and after a complex categorization task. Metacognitive experiences refer to awareness and feelings about a task. The results highlighted a link between the Feeling Of Familiarity (FOF), one of concept of metacognitive experience and categorization performances and between coping strategies and metacognitive experience. There was also a link between coping strategies and metacognitive experiences, more specifically emotional outbursts. Finally, self-criticism appeared to be a good predictor of part of the FOF prior to the task. Self criticism is the ability to people to consider he is partly responsible of a situation.

In conclusion, the participants' poor performances could be explained by their inefficient coping strategies and metacognitive experiences. Our results highlight the necessity to coach adults with severe and moderate intellectual disabilities in metacognitive experiences and emotional coping strategies before, and after a cognitive task.

Keywords: severe learning disability, metacognition, coping strategy 


\section{Introduction}

\section{Literature review}

According to ICD 11 (2018), intellectual disability is « a group of developmental conditions characterized by significant impairment of cognitive functions, which are associated with limitations of learning, adaptive behavior and skills». There are also different diagnostic levels (ligt, moderate, severe...). For example, according to the WHO (World Health Organization, 2018), severe intellectual disability corresponds to people who do not exceed a mental age of six to seven years old. Cognitive disorders were associated with varying degrees of motor and psycho-behavioral disorders However, it cannot only be limited to evaluating intellectual potential, which depends on the rate of knowledge acquisition, and more specifically on real potentialities. The potential of a participant can be measured, for example, by comparing his/her performance on a task solved alone with that on the same task after training. If the score increases, the person can be considered to have potentialities (Cebes, Paour 2012). In fact, intellectual disability, from a cognitive and developmental point of view, can be perceived in two ways: as a difference (less efficient than people having the same chronological age) or as delayed (information processing efficiency of a younger "neurotypical" child). In their daily life, people with intellectual disabilities are very dependents of the others, especially to make choices, to adapt to their environment, to express their desire, need, that's why we are interested here.

According to Borkowski and Cavanaugh (1979), failure in memory tasks (memory strategies) could be explained by inefficient executive functioning and metacognitive knowledge. Peoples' performances on some tasks can be enhanced by providing them with tasks taking into account their skills (Bray et al., 1998; Groen et al., 2006). However, for high-level tasks which require ability to control attention, their results are very poor (Kavale, Forness, 1999; Lanfranchi et al. 2004). In accordance with these studies, and in line with Courbois and Paour (2007), we considered that the large observed variability across different tasks was linked more to inefficient development of individual potentiality than to a real generalized deficit. Moreover, few studies have focused on the learning performance of adults with intellectual disabilities. However, with the increase in life expectancy of this public it seems essential to investigate this subject.

\section{Metacognition}

Metacognition can be defined as the awareness of one's own mental functioning and was developed in the 1970s (Flavell 1979). It is an alternative way to understand some aspects of mental functioning of people with learning disabilities, which does not refer directly to cognitive potential 
but to the abilities to manage it (Flavell, Wellman, 1977; Brown et al., 1987). Efklides and Misaimidi (2010) described three metacognitive components: knowledge, ability and experiences. Metacognitive experiences refer to awareness and feelings when encountering a task and processing information that is specific to it (Efklides, 2008). In other words, feelings and judgments made about a task during learning, remembering and/or reasoning (Flavell, 1979; Efklides, 2001). This is the affective side of metacognition (Efklides et al. 2006). When individuals have to solve a problem, various past experiences affect their judgments relating to their ability to solve it, based on their the feeling of familiarity (FOF), of difficulty (FOD), the estimate of effort required (EOE), the estimate of solution correctness (EOSC), the interest (I) and the liking of the problem (Pleasure), the feeling of confidence in the solution produced (FOC), and the feeling of satisfaction from it (FOS). These metacognitive experiences could come to mind before, during or after solving the problem. In this study we only focused on these metacognitive experiences because few information were known about the role of this affective side of metacognition and cognition in people with learning disabilities.

Brown (1978) and Flavell (1978) found that many people with learning disabilities had poor metacognitive functioning. Numerous studies, notably by Courbois and Paour (2007), made the same observation and noted the importance of seeking metacognition to limit learning disabilities. So, the role of metacognitive components in mental functioning is crucial as the ability to activate execution and control strategies (Schneider, Lockl, 2002, Tarricone, 2011). Moreover, according to these authors, metacognitive components would be less efficient for people with severe learning disabilities than for "neurotypical" people at the same age. Other authors (Cornoldi, Campari, 1998) have observed that tasks requiring voluntary effort and a conscious analysis of cognitive loads cause difficulties, which correspond to metacognitive difficulties. Some research suggests that the complexity of setting up the metacognitive process (strategies) is linked to these difficulties (Flavell, Wellman, 1977; Cornoldi, Campari, 1998). However, these researches focus on knowledge and skills metacognitive components.

Little is known about the role of metacognitive experiences in cognitive performance of people with intellectual disabilities. Bruderlein $(1998,2000)$ considers that they perform less well than "neurotypical" people on categorization tasks. However, categorization is a basic cognitive process used to organize and understand the world around us and it is therefore fundamental. For example, in their daily lives, people with intellectual disability don't find the objects necessary to set the table by thematic classification or associate an object to a concept by taxonomic classification...

Among the eight different metacognitive experiences measured, the feeling of familiarity (FOF) could therefore be a good metacognitive experience, which could explain in part the variability in categorization performances of this population. Tyng et al. (2017) explained how emotions and 
complexity could interact and affect performance; negative emotions could overload the working memory and have a negative effect on performance. This difficulty can be real (cognitively complex) or perceived. In the case of perceived difficulty, this metacognitive experience is called feeling of difficulty (FOD). Several studies have shown the importance of FOD on cognitive performance, such as in problem solving or mathematical problems in 246 "neurotypical" 11-yearold students of 5th grade (Efklides, 2001, 2006; Blinded for peer review) or children with conduct disorders (Pennequin, Lunais, 2013). One study of Nader-Grosbois (2014) observed that adolescents (11-16 years old with learning disabilities) are lower in performance, self-regulation and metacognition than neurotypical children. Other metacognitive experiences are linked to cognition in "neurotypical" children and adolescent populations, but to a lesser extent than FOD. Nothing is known about adults with learning disabilities.

This affective side of metacognition (metacognitive experiences) seems an interesting focus to study among people with learning disabilities because they have difficulties in interpreting their internal state, controlling their behavior and planning an action (Sovner, Hurley, 1986). Other research has highlighted that this population has difficulties in setting up coping strategies, especially when struggling to regulate their emotions (e.g., excitation) (Benson, Fuchs, 1999; Harley, MacLean, 2005; Lunsky, 2003). This emotional self-regulation is essential during a cognitive task for it to be completed efficiently (Kuhl, 2000). Indeed, working memory is overloaded when the level of an emotion is too high and this can affect the overall cognitive performance. However, previous research has shown that problem solving performance could be predicted more efficiently through metacognitive experiences than emotions (Efklides, Petkaki, 2005; Pennequin, Lunais, 2013). A study blinded for peer review observed that coping strategies appeared to be linked to some metacognitive experiences, but not to problem solving performance: children with a tendency to express high emotions without control (shouting, screaming or getting angry) were more likely to feel that the problem was difficult and unfamiliar and to think that their response would be incorrect. These positive or negative representations in a learning situation (e.g., metacognitive experiences) lead individuals to be motivated, or not, to solve the task and affect the degree to which they will solicit their cognitive resources.

Gavornikova-Baligand and Deleau (2004) proposed a categorization system that enables the organization of knowledge into categories and its usage to be understood. Indeed, categorization is a major cognitive process in decision-making and in all forms of interaction with the environment, such as the perception and understanding of concepts and objects (Jordan, Russel 1999). This process requires executive functions, attentional capacities, and metacognition. It therefore becomes a complex process for people with learning disabilities because during a cognitive task they do not know how to create their personal strategies which are related to metacognition (Bray et al., 1998; Buchel, 2003). 


\section{Purpose of the study}

The aim of this study was therefore to assess the links between coping strategies, metacognitive experiences and categorization performance in adults suffering from learning disabilities. More precisely, three questions were explored:

- 1. Are metacognitive experiences before and after solving the task, and particularly Feeling Of Difficulty and Feeling Of Familiarity, linked to the people's categorization performance?

- 2. Are coping strategies linked to metacognitive experiences before and after solving the categorization task? In particular, we postulate that some maladaptive coping strategies are associated with negative metacognitive experiences. In other words, people who become angry, who wish the problem would go away or had never occurred or who blame others are more likely to have high negative feelings and expectations about the categorization task.

- 3. Are coping strategies linked more to metacognitive experiences than to categorization performance, as observed with other populations?

\section{Methodology}

Sample

A sample of 32 participants was recruited in institutions supporting adults with learning disabilities in Loir et Cher (France). They had a verbal or a non-verbal mode of communication to ensure the exactness of their responses. All the participants had to carry out the whole procedure. People with excessive sensory impairment were excluded. The participants and their legal representatives gave their consent to take part in this research work.

32 people with learning disabilities were recruited. The participants were for the most part under guardianship (over 84\%), some were permanently institutionalized to ensure their daily life with multiple $(25 \%)$ or partial $(28 \%)$, disabilities, in a MAS or FAM/FDV (specialized reception center in France with different degrees of autonomy). Other profiles were in day care (47\%) and live at home alone with help or with their family. Some participants can work on dedicated sites part-time $(15,63 \%)$.

The participants presented intellectual deficiency for the most part linked to a genetic (Downs Syndrome, Fragile X syndrome), neurological (epilepsy, etc.), neonatal or unknown origin. The participants were between 23 and 70 years old (mean: 42.8, SD: 14.3) and there were 16 women and 16 men.

\section{Instruments}

Tool that measure disability 
The Raven's (1936) progressive color matrices task was used as no test had previously been performed, we choose to use Each participant had to complete a series of abstract and incomplete geometric figures among six items and with several levels of difficulty, A: completing a figure, $\mathrm{AB}$ and $\mathrm{B}$ : Each series includes 12 figures, $\mathrm{A}$ : a piece of a puzzle to be completed from 6 choices. AB: Find the 4 th piece to complete a set among 6 choices, B: find the 4th figure to complete a logical sequence among 6 pieces. the sum of the correct results of the 3 series is calculated and then associated with a developmental age according to the calibration defined by the test. More precisely, the PM 47 set, primarily adapted for children from 4 to 11 years old, was chosen because it was suitable for the sample population. This set has the advantage of not imposing a long and expensive task in terms of attention and emotion and assesses the overall intelligence of the people by evaluating their analogical reasoning skills (Prahbakaran, et al. 1997; Gregoire, 2004).

Tool that measure adaptability of people

The Kidcope (Spirito et al. 1988), used and revalidated for example by Rathner and Zangerle (1996) Cheng and Chan (2003). This test used to evaluate the coping strategies of people in front of a complex situation, was chosen for this study because it is relatively brief, assesses specific coping strategies, and has good reliability and validity. The children's version was chosen because the formulations are simpler than the adult version. This test is mainly used to evaluate people who have autism spectrum disorders or significant stress and thus was suitable for our population. This Kidcope scale has 15 questions in relation to 11 different types of coping strategy, (use a distractor as watch tv, social withdrawal as stay alone, cognitive restructuration as see the good side of things, self criticism, blame other, find a solution, emotional outburst as cry, magic thinking, social support as see my family, resignation). with a maximum of two questions per strategy. Four of these strategies are approach-oriented and thus generally considered as positive or adaptive and seven are escape-oriented and thus generally considered as negative or maladaptive (Spirito et al. 1988). Participants had to indicate how often they used a particular coping strategy and this frequency was assessed by asking the participants to rate each strategy on a Likert 4-point: never, rarely, often or frequently. Higher scores indicate participant uses regularly this strategy whereas lower scores indicator that participant doesn't use it. For strategies having two items, the mean of the two items was calculated (Spirito et al., 1988). For example, one question was on self-criticism: "When faced with a situation that has worried you, do you often think 'it's my fault?". Here it is a question of attributing an internal cause to a negative event linked to the person. Or for magic thinking, "I want the problem to go away".

Tool that measure metacognitive experience of people 
Metacognitive performances were evaluated before and after the experiment. Participants answered the Metacognitive Experiences Questionnaire $(M E Q)$ created by Efklides (2002a), validated in French by Pennequin and Lunais (2013). This involved asking the people to evaluate their upcoming performance on the proposed task after hearing the instruction. The prospective form has five items covering the feeling of familiarity (FOF) ("Does this problem seem familiar to you?"), the feeling of difficulty (FOD) (“Does this problem seem difficult?"), an estimate of required effort (EOE), and an estimate of solution correctness (OESC), and one question about the interest of the problem ("Is this problem interesting?"). The retrospective version has seven items: the interest and feeling of pleasure in doing the task (FOF), the feeling of difficulty (FOD), the estimate of effort (EOE), the estimate of the solution correctness (FOD) the feeling of confidence in the solution produced (FOD), and the feeling of satisfaction from it (FOS). Some items are the same before and after the task in order to compare the participants' responses. example: EOE before: the task seems difficult to you? after, did you have to make efforts to solve the task? The responses were rated on $a$ 4-point Likert scale, ranging from 1= not at all, to $4=$ very much.

Tool that resume categorization

Categorization was evaluated by the items of the subtest Concept Identification Scale of the Wechsler Intelligence Scale for Children IV (Wechsler 2005). This task was chosen because of the possibility for participants to categorize in function of different criteria that could have a thematic or taxonomic link between them. Points were attributed to maximize the variance of the scores obtained. A range of 0 to 3 points were awarded ( 1 for a perceptual response, 2 for a thematic answer, 3 for a taxonomic answer and 0 for an error). Indeed, some points were attributed if the participant detected a common trait between items, even if this trait was not taxonomic. In fact, it has been shown that perceptual and thematic categorizations represent a lower level of categorization development than taxonomic categorization (Piaget \& Inhelder, 1959). Each participant had to associate one of the color objects from the first line with one from the second line. There are two levels of difficulty in the task, either to associate an image among 4 or among 6.

\section{Procedure}

The participants were individually evaluated by the institution's psychologist in his office. This psychologist has been practicing for 10 years and regularly performs neuropsychological tests on individuals. Firstly the psychologist explained the procedure of the experiment to the participant who then completed Raven's progressive matrices task test before filling out the kidcope questionnaire. 
Secondly, the psychologist explained the categorization task, after which each participant completed the prospective MEQ questionnaire. To do this, a sliding scale rated from 1 to 5 with smileys was used. This more visual support enabled participants to be more involved in the task, because a task associating a feeling and a number would have been too complex for this population. The participants then completed the categorization task by choosing one item per line. An example was given to each participant to ensure he/she had understood what the task required. Finally, at the end of the experiment the participant completed the retrospective MEQ questionnaire.

\section{Data analysis and results}

\section{Disability measure}

In this study, 30 participants have a severe learning disability and 2 present a moderate learning disability (mean of age developmental was 4.64 years old, and SD: 1.21) on Raven's matrices task.

\section{Categorization performances}

Firstly, we aimed to identify the kind of classification used in the proposed task. As expected, most people used the taxonomic form (47.92\%), followed by the perceptual form $(10.42 \%)$ and then the thematic form $(5.90 \%)$. It should be noted that the error rate was very high $(35.76 \%)$. In fact, participants don't find any categorization for some items in categorization task. No significant link was observed between chronological age, developmental age (Raven Matrices), or gender and performance in categorization tasks.

\section{Correlations in $M E Q$ and in Kidcope}

Before performing the step-by-step regression analyses to tested the two hypotheses, Correlation matrices between the MEQ items.

\section{Insert Table 1 here}

Retrospective FOC was positively correlated with retrospective EOE (0.37) and FOD (0.62), OESC (0.38) and retrospective FOF (0.52). Prospective FOF was correlated with retrospective EOE (0.37), prospective OESC and prospective FOD (0.51). prospective OESC and retrospective EOE (0.53). Finally, retrospective FOF and retrospective FOD (-.49).

Correlation matrices between the Kidcope items were generated and the results are shown in Table 2.

\section{Insert Table 2 here}

The results shown that social withdrawal was correlated with self-criticism (0.38). Problem solving was correlated with magic thinking (0.54), distractor (0.47) and social support (0.57). Social support 
was also correlated with distractor (0.46) and magic thinking (0.38). Finally, blame was correlated with resignation $(0.43)$.

\section{Links between metacognition experience and categorization performances}

A series of linear regression step-wise analyses were performed, in which the hierarchical order of each predictor depended on its partial correlation with the independent variable. The choice of the first variable was based on the highest correlation and the following variables were based on its partial correlation. However, when a variable is added to the model, Statistica software assesses both whether the variable contributes significantly and whether the least contributing variable remains significant. Non-significant variables can thus be removed. Separate analyses were carried out for prospective and retrospective phases.

The last step-by-step regression analysis, corresponding to the first hypothesis, explored whether metacognition was linked to categorization performance. Thus, the independent variables were the five metacognition experiences of the prospective phase, and the dependent variable was the categorization performance. The results of the most suitable model are shown in Table 3 and correspond to the first step of the analysis.

Insert table 3 here

They show that the FOF in the prospective phase was significantly and negatively linked to the categorization performance. The participants' familiarity with the task explained $12.54 \%$ of the variance of the categorization performance. Counter intuitively, the higher FOF was before solving the task the worse the performance was.

Finally, a step-by-step ascendant regression analysis with categorization performance and retrospective metacognition experiences as predictors was performed. This analysis shows that none of the metacognitive experiences in the retrospective phase had a significant link with the categorization performances (all $\mathrm{p}>0.5$ ).

\section{Links between coping strategies and categorization performances}

The step-by-step regression analysis explored whether coping strategies could predict a significant part of the categorization performance. The predictors were thus the 11 strategies used by participants on the Kidcope questionnaire and the dependent variable was the categorization performance. The results of the most suitable model are shown in Table 4 and correspond to step 2.

Insert Table 4 here

They show that some emotional coping strategies were linked significantly to the categorization performance. About $15 \%$ of the variance of the categorization performance could be explained by emotional regulation and more specifically by emotional outbursts and magical thinking. Thus the more a participant regulated his/her emotions negatively through emotional outbursts, the worse his/her performance was. In contrast, the more people used magical thinking, 
the better their categorization performance was.

\section{Link between metacognitive experience and coping strategies}

The step-by-step regression analysis explored whether coping strategies could predict a significant part of the metacognitive experiences. Thus, the predictors were the 11 strategies used by participants on the Kidcope scale and the dependent variable was only the prospective FOF because no significant metacognitive experiences in the retrospective phase had a significant link with the categorization performance. The results of the most suitable model are shown in Table 5.

\section{Insert Table 5 here}

They show that more than $26 \%$ of the variance of the FOF could be explained by self-criticism. Thus, the more people criticized themselves the higher their FOF was.

\section{Discussion}

The main aim of this study was to investigate the links between metacognitive experiences, coping strategies and performances on a categorization task in adults with learning disabilities. The results firstly show that the categorization task was often not completed correctly, as shown by the high error rate. These results are similar to previous results obtained by Bruderlein (1998) who considered that this population was less efficient than "neurotypical" people in categorization tasks. Indeed, this task is a fluid intelligence task that allows for variance in scores and is commonly used to test the level of intellectual efficiency. It allows for variance, with neither a floor nor ceiling effect.

Our first hypothesis was that some metacognitive experiences were linked to the categorization performance, particularly FOD and FOF. The results show that categorization performance was negatively linked to the FOF only before solving the problem. No other metacognitive experience was linked to categorization performance either before or after solving the task. Even if the literature reports that FOD is linked to problem solving performance in "neurotypical" children (Efklides, 2001, 2006; Blinded for peer review) and children with conduct disorder (Pennequin \& Lunais, 2013), these results were not found for adults with severe learning disabilities. Unexpectedly, we found that only FOF was negatively linked to performance. Moreover, this result shows that a positive feeling about the task was not necessarily associated with good performance. We could suppose that a high FOF leads to a decrease in attentional vigilance and reduced mobilization of resources. Thus, we can conclude that some negative feelings before the task are important to perform better. After solving the categorization task, no metacognitive experiences were linked to the performance, contrary to results observed in other populations ("neurotypical" 
teenagers or teenagers with conduct disorders, $($-average age $=16.95$ years, $\mathrm{sd}=1.46$ years-) (Pennequin, Lunais, 2013; Blinded for peer review). We can interpret this result in two ways: either adults with learning disabilities do not ask themselves question about solving the task and do not construct feelings and estimations about their own performance; or people with learning disabilities make judgments and have feelings about the task but they do not use them to adapt metacognitive strategies and optimize their performance. Thus, they cannot associate any metacognitive experiences to their performance to store them in memory. Without these associations in memory, metacognitive experiences cannot help them in a future categorization task. According to Perron (1991) and Coroir, Sordes-Ader (2001, the most important factor for this population seems to be the relation with the experimenter and the pleasure in doing an exercise with another person. Consequently, performance may be less important than for "neurotypical" people. Moreover, adults with learning disabilities may not have really understood that they had failed because the experimenter continued to smile and speak with them, without getting angry or shouting. Finally, they could have presented some compensatory strategies due to low performance (Diederich, Moyse 1995, Ninot, et al 2000). In addition, FOF does not necessarily correspond to a true feeling: in other words, the participant could have a high FOF even though the task is novel. In this case, this reflects an inefficiency of the affective side of metacognition.

The second hypothesis concerned links between coping strategies and categorization performance and suggested that emotional regulation strategy, more specifically an emotional outburst, was linked to categorization performance. Our results confirm that the outburst was a maladaptive emotional regulation which did not allow relevant attention to perform the task. This finding is in line with Benson and Fuchs' research (1999), which considers that people struggle to develop an adaptive coping strategy when emotions are high, particularly regarding negative emotion.

Negative emotions can be related to life events considered as anxious, such as a complex task or an assessment in the presence of an experimenter. Benson and Fuchs (1999) observed people with learning disabilities at their workplace using a questionnaire to identify which coping strategies were employed, such as aggression, isolation or talking to someone. In our results, no appropriate strategies appeared. An explanation could be that in their study, the people had mild to moderate learning disabilities, but that with greater learning disability fewer coping strategies are appropriate.

Our results confirm Kuhl's (2000) work: Emotional self-regulation is essential during a cognitive task to be efficient. These results tend to indicate that our population was not able to use an adaptive emotional strategy to optimize their cognitive processes necessary to solve the task. Hartley and MacLean (2009) reported that previous studies focusing on coping strategies employed were based on caregiver or family observations but never on the individuals own perception of coping 
strategies. Thus, while previous research has shown that the coping strategies employed were inappropriate, it seems that in our study participants corroborate themselves their inappropriate strategies, even if they did not understand all the consequences of them.

Finally, in our study no adaptive coping strategies (e.g., cognitive restructuring or social support) had a significant link with categorization performance, there were only maladaptive strategies. These results are supported by Borkowski and Cavanaugh's (1979) work which considers that it is necessary to train people specifically in coping strategies in order to increase their performance in cognitive tasks and enable them to transfer these strategies. Indeed, if professionals working with people with learning difficulties can support these people in regulating their emotions and strategies, their learning potential would be increased, as suggested by Courbois and Paour (2007). To conclude children with intellectual disabilities should be taught adaptive coping strategies so that they do not continue using inappropriate strategies that do not help them to optimize their cognitive performance.

The third hypothesis was that coping strategies could be linked to metacognitive experience. In particular, we hypothesized that some maladaptive coping strategies would be associated with negative metacognitive experiences. Our results show that self-criticism was a good predictor to explain some of the metacognitive performance before the categorization task (FOF). Consequently, the more people are conscious of their own difficulties and consider they could find a solution to this situation, the greater FOF is. We can suppose that this self-criticism can be linked to apprehension relating to the experiment, "An exercise... I will again be in difficulty", without considering the task specifically, but perceiving the situation as anxiety inducing, as an assessment with an experimenter. Thus, self-criticism could be linked to a stress factor or to weak self-esteem.

This self-criticism could also explain the poor performance in the categorization task. For the coping strategies appear to be linked to some metacognitive experiences, but not directly to the problem solving performance: thus a "neurotypical" child who tends to express emotions without control is more likely to feel that the problem is difficult and unfamiliar and to think that his/her response will be incorrect. However, in our study of adults with severe learning disabilities, we observed a direct link with categorization performance. To conclude children with intellectual disabilities should be taught adaptive coping strategies to prevent them from learning inappropriate strategies which do not help them to optimize their cognitive performance. In addition, appropriate strategies should be instilled in people throughout their development to reinforce them over time and different learning situations should be maximized to enable people to react appropriately according to the context.

\section{Conclusion}


While many studies have focused on the performance of children with learning disabilities, few have focused on an adult population. Our study shows that the metacognitive functioning and coping strategies of the latter were not always efficient, which may explain in part their low performance on the categorization task. They did not use the same metacognitive experiences to optimize their cognitive performance as other populations. They did not use the usual FOD, but only the FOF prior to solving the task and this resulted in a poorer performance. In addition, it is not certain that their FOF corresponded to reality. A specificity of this population is that some emotional coping strategies are directly linked to performance. In addition these coping strategies are considered as maladaptive. It also appears that some unsuitable coping strategies are predictive of metacognitive experiences before the categorization task. These observations indicate that they have difficulties in adopting appropriate strategies but also in regulating their emotions according to the situation. Finally, they seem to have a misperception of their performance and behavior. Thus to conclude, our results highlight the necessity to coach this population regarding metacognitive experiences and emotional coping strategies before, and after a cognitive task.

\section{$\underline{\text { References }}$}

Benson, B., Fuchs C. (1999). Anger-arousing situations and coping responses of aggressive adults with intellectual disability. Journal of Intellectual and Developmental Disability, 24 (207-214).

Borkowski, J.G., Cavanaugt, J.C. (1979). Maintenance and generalization of skills and strategies by the retarded. In N.R. Ellis (dir.), Handbook of Mental Deficiency (569-617). Hillsdale (NJ): Erlbaum.

Bray, N. W., Huffman, L., Grupe, L. (1998). Un cadre conceptuel pour l'étude des déficiences et des compétences de mémorisation chez les enfants présentant un retard mental. In F. P. Büchel, J.-L.

Brown, A. (1978). Knowing When, Where and How to Remember: A problem of metacognition, in R. Glaser (Ed.) Advances in Instructional Psychology, vol. 1. Hillsdale: Lawrence Erlbaum.

Brown, A. L., Bransford, J. D., Ferrara, R. A., Campione, J. C. (1987). Learning, remembering, understanding. In P. H. Mussen (ed.), Handbook of child psychology 3 (77-166). New York: Wiley, 77-166.

Bruderlein , P. (1998). Gestion des connaissances et retard mental : Les effets de l'expertise. In: F.P. Bûchel, J.L. Paour, Y. Courbois et U. Scharnhorst (Eds.), Attention, mémoire, apprentissage. Études sur le retard mental. Édition SZH/SPC.

Bruderlein, P. (2000). Catégorisation et efficience intellectuelle: Influence de l'explication des connaissances. Thèse de Doctorat en Psychologie, Université de Provence, Aix -Marseille I. 
Büchel, F. (2003). Les processus d'apprentissage chez des personnes ayant un retard mental ou des difficultés d'apprentissage : Quelles théories, quelles recherches ? In Gisela Chatelanat éd., Éducation et enseignement spécialisés : ruptures et intégrations (119-154). Louvain-la-Neuve, Belgique: De Boeck Supérieur.

Cèbe, S., Paour, J. (2012). Apprendre à lire aux élèves avec une déficience intellectuelle. Le français aujourd'hui, 177(2), 41-53.

Coroir, C., Sordes-Ader, F. (2001). Vivre l'adolescence dans un corps différent. Handicap (Paris. 1999), (89), 45-60.

Cheng, S, T., Chan. A, C. M. (2003). Factorial Structure of the Kidcope in Hong Kong Adolescents. The Journal of Genetic Psychology, 164 (3): 261-266.

Cornoldi, C., Campari, S. (1998). Connaissance métacognitive et contrôle métacognitif dans le retard mental. In F. P. Büchel, J.-L. Paour, Y. Courbois, \& U. Scharnhorst (Eds), Attention, mémoire, apprentissage. Études sur le retard mental (119-128). Lucerne.

Courbois, Y., Paour, J.-L. (2007). Le retard mental. In book: Psychologie du développement et de l'éducation. Presses Universitaires de France, pp 377-406.

Diederich, N., Moyse, D. (1995). Interactions et images de soi chez des personnes dites handicapées mentales. Revue européenne du handicap mental, (5), 15-27.

Efklides, A. (2001). Metacognitive experiences in problem solving. In A. Efklides, J. Kuhl, \& R.M.Sorrentino (Eds.), Trends and prospects in motivation research ( 297-323). Dordrecht, The Netherlands: Kluwer Academic Publishers.

Efklides, A. (2002a). Feelings as subjective evaluations of cognitive processing: How reliable they are? Psychology: The Journal of the Hellenic Psychological Society, 9, 163-184.

Efklides, A., Petkaki, C. (2005). Effects of mood on students' metacognitive experiences. Learning and Instruction, 15, 415-431.

Efklides, A., Kourkoulou, A., Mitsiou, F., \& Ziliaskopoulou, D. (2006). Metacognitive knowledge of effort, personality factors, and mood state: Their relationships with effort-related metacognitive experiences. Metacognition and Learning, 1(1), 33-49.

Efklides, A. (2008). Metacognition: Defining its facets and levels of functioning in relation to selfand co-regulation. European Psychologist, 13, 277-287.

Efklides, A. and Misaimidi, P. (2010). Trends and Prospects in Metacognition Research, ed. A. Efklides and P. Misaimidi. New York: Springer. 
Flavell, J. H.(1978). Metacognitive development. In J. M. Scandura, C. J. Brainerd (Eds.), Structural/process theories of complex human behavior. Alphen a. d. Rijn, The Netherlands: Sijthoff \& Noordhoff.

Flavell, J. H. (1979). Metacognition and cognitive monitoring. A new area of cognitivedevelopmental inquiry. American Psychologist, 34, 906-911.

Flavell, J. H., Wellman, H. M. (1977). Metamemory. In R. V. Kail \& J. W. Hagen (Eds.). Perspectives on the development of memory and cognition, Hillsdale, N.J : Erlbaum.

Gavornikova-Baligand, Z., \& Deleau, M. (2004). La catégorisation chez les adultes déficients intellectuels: déficit de structuration ou de mobilisation? Revue francophone de la déficience intellectuelle, 15, 5-21.

Grégoire, J. (2004). Chapitre 5. Les tests factoriels d'intelligence. In: J. Grégoire, L'examen clinique de l'intelligence de l'adulte (pp. 219-239). Wavre, Belgique: Mardaga.

Groen, M.A., Laws, G., Nation, K., Bishop, D. (2006). A case of exceptional reading accuracy in a child with Down syndrome: Underlying skills and the relation to reading comprehension. Cognitive Neuropsychology, 23 (8), 1190-1214.

Harley, S.L., MacLean, W.E., Jr. (2005). Perceptions of stress and coping strategies among adults with mild mental retardation: Insight into psychological distress. American Journal on Mental Retardation, 103, 209-224.

Jordan, M. I., S. Russel. (1999). 'Categorization'. In: The MIT Encyclopedia of the Cognitive Sciences. The MIT Press, Cambridge, Massachusetts. S. 104-106.

Kavale, K.A., Forness, S.R. (1999). Efficacy of special education and related services. Washington: AAMR.

Kellett, S., Beail, N., Newman, D. W and Hawes, A. (2004). The factor structure of the Brief Symptom Inventory: Intellectual disability evidence, Clinical psychology and psychotherapy, 11: 275-81.

Kuhl, J. (2000). A Functional-Design Approach to Motivation and Self-Regulation: The Dynamics of Personality Systems Interactions. Handbook of Self-regulation.

Lanfranchi, S., Cornoldi, C., Vianello, R. (2004). Verbal and visuospatial working memory deficits in children with down syndrome. American Journal on Mental Retardation, 109(6), 456-466.

Lunsky, Y. (2003). Depressive symptoms in intellectual disability: Does gender play a role ? Journal of Intellectual Disability Research, 47, 417-427. 
Nader-Grosbois, N. (2014). Self-perception, self-regulation and metacognition in adolescents with intellectual disability. Research in developmental disabilities, 35(6), 1334-1348.

Ninot, G., Bilard, J., Delignières, D., Sokolowski, M. (2000). Effects of integrated sport participation on perceived competence for adolescents with mental retardation. Adapted Physical Activity Quarterly, 17(2), 208-221.

Pennequin, V., Lunais, M. (2013). La métacognition chez les adolescents présentant des troubles de la conduite et du comportement : Humeurs et expériences métacognitives. Enfance, 4, 303-322.

Pennequin, V. Questel, F. Delaville, E. Delugre, M. Maintenant, C. (in press). Metacognition and emotional regulation in children from 8 to 12 years old. British Journal of Educational Psychology.

Perron, R. (1991). Les représentations de soi. Toulouse: Privat.

Piaget, J., Inhelder, B. (1959). La genèse des structures logiques élémentaires. Neuchâtel : Delachaux \& Niestlé.

Prabhakaran, V., Smith, J., Desmond, J. E., Glover, G. H., Gabrieli, J. D. E. (1997). Neural substrates of fluid reasoning: An fMRI study of neocortical activation during performance of the Raven's Progressive Matrices Test.Cognitive Psychology, 33, 43-63.

Rathner G, Zangerle M. (1996).Coping strategies of children and adolescents with diabetes mellitus: the German language version of KIDCOPE. Zeitschrift fur Klinische Psychologie, Psychiatrie und Psychotherapie. 44(1):49-74.

Raven, J. C. (1936). Mental tests used in genetic studies: The performance of related individuals on tests mainly educative and mainly reproductive. Msc Thesis, University of London.

Schneider, W. \& Lockl, K. (2002). The development of metacognitive knowledge in children and adolescents. In Perfect, T. \& Schwartz, B. (Eds.), Applied metacognition. Cambridge, UK: Cambridge University Press.

Sovner, R., Hurley, A. D. (1986). Four factors affecting the diagnosis of psychiatric disorders in mentally retarded persons. Psychiatric Aspects of Mental Retardation Reviews, 5(9), 45-49.

Spirito, A., Stark, L.J., \& Williams, C.A. (1988). Development of a brief checklist to assess coping in pediatric patients. Therapeutic issues. Journal of Pediatric Psychology, 13, 555-574.

Tarricone, P. (2011). The taxonomy of metacognition. Psychology Press.

Tyng, C. M., Amin, H. U., Saad, M., \& Malik, A. S. (2017). The Influences of Emotion on Learning and Memory. Frontiers in psychology, 8, 1454. 
Wechsler D. (2005). Manuel d'administration et de cotation du WISC-IV. Paris: Editions du Centre de Psychologie Appliquée.

World Health Organization. (2018). ICD-11. International Classification of Diseases 11th Revision. The global standard for diagnostic health information

\begin{tabular}{|c|c|c|c|c|c|c|c|c|c|c|c|}
\hline & Means & SD & $\begin{array}{c}\text { FOF } \\
\text { prospectif }\end{array}$ & $\begin{array}{c}\text { EOE } \\
\text { prospectif }\end{array}$ & $\begin{array}{c}\text { FOD } \\
\text { prospectif }\end{array}$ & $\begin{array}{l}\text { OESC } \\
\text { prospectif }\end{array}$ & $\begin{array}{c}\text { FOF } \\
\text { retrospectif }\end{array}$ & $\begin{array}{c}\text { EOE } \\
\text { retrospectif }\end{array}$ & $\begin{array}{c}\text { FOD } \\
\text { retrospectif }\end{array}$ & $\begin{array}{l}\text { FOC } \\
\text { retrospectif }\end{array}$ & $\begin{array}{c}\text { FOS } \\
\text { retrospect }\end{array}$ \\
\hline FOF prospectif & 2,25 & 1,46 & 1,00 & 0,21 & 0,28 & 0,26 & $-0,19$ & $0,37^{\star}$ & $0,47^{\star}$ & $-0,13$ & 0,16 \\
\hline EOE prospectif & 2,66 & 1,33 & - & 1,00 & 0,34 & 0,23 & 0,06 & 0,13 & 0,29 & $0,37^{\star}$ & 0,23 \\
\hline FOD prospectif & 3,19 & 1,15 & - & - & 1,00 & $0,51^{*}$ & 0,23 & 0,22 & 0,26 & $0,62^{*}$ & $-0,13$ \\
\hline OESC prospectif & 3,44 & 0,82 & - & - & - & 1,00 & 0,18 & $0,53^{*}$ & 0,15 & $0,38^{\star}$ & 0,32 \\
\hline FOF retrospectif & 3,69 & 0,64 & - & - & - & - & 1,00 & $-0,31$ & $-0,49^{\star}$ & $0,52^{\star}$ & 0,19 \\
\hline EOE retrospectif & 3,34 & 0,90 & - & - & - & - & - & 1,00 & 0,34 & 0,00 & 0,07 \\
\hline FOD retrospectif & 2,28 & 1,35 & - & - & - & - & - & - & 1,00 & $-0,13$ & 0,04 \\
\hline FOC retrospectif & 3,81 & 0,78 & - & - & - & - & - & - & - & 1,00 & $-0,04$ \\
\hline FOS retrospectif & 3,97 & 0,18 & - & - & - & - & - & - & - & - & 1,00 \\
\hline
\end{tabular}

Tableau 1: Means, standard deviations between prospective and retrospective items of the Metacognitive

\section{Experience Questionnaire.}

Note :

FOF:Feeling Of Familiarity

EOE : Estimation Of Effort

FOD :Feeling Of Difficulty

OESC : Estimate Of Solution Correctness

FOS :Feeling Of Satisfaction

$* \mathrm{p}<.05$

Table 2. Means, standard deviations and correlations between prospective and retrospective items of

\begin{tabular}{|c|c|c|c|c|c|c|c|c|c|c|c|c|}
\hline & Means & SD & distractor & $\begin{array}{c}\text { social } \\
\text { withdrawal }\end{array}$ & $\begin{array}{l}\text { cognitive } \\
\text { restructuring }\end{array}$ & $\begin{array}{c}\text { self } \\
\text { critism }\end{array}$ & blame & $\begin{array}{l}\text { problem } \\
\text { solving }\end{array}$ & $\begin{array}{l}\text { emotional } \\
\text { regulation }\end{array}$ & $\begin{array}{l}\text { magic } \\
\text { thinking }\end{array}$ & $\begin{array}{l}\text { social } \\
\text { support }\end{array}$ & resignation \\
\hline distractor & 2,06 & 0,97 & 1,00 & $-0,01$ & 0,20 & $-0,09$ & 0,09 & $0,47^{\star}$ & 0,11 & 0,32 & $0,46^{\star}$ & 0,00 \\
\hline social withdrawal & 1,77 & 1,06 & - & 1,00 & 0,32 & $0,38^{*}$ & $-0,15$ & 0,23 & 0,09 & 0,30 & 0,11 & $-0,04$ \\
\hline cognitive restructuring & 2,28 & 0,99 & - & - & 1,00 & 0,23 & 0,18 & 0,22 & 0,22 & 0,13 & 0,04 & $-0,25$ \\
\hline self critism & 0,56 & 1,13 & - & - & - & 1,00 & 0,24 & 0,01 & 0,29 & 0,15 & $-0,28$ & 0,19 \\
\hline blame & 0,88 & 1,31 & - & - & - & - & 1,00 & 0,26 & 0,25 & 0,22 & $-0,11$ & $0,43^{\star}$ \\
\hline problem solving & 1,64 & 1,21 & - & - & - & - & - & 1,00 & 0,32 & $0,54^{*}$ & $0,57^{\star}$ & 0,14 \\
\hline emotional regulation & 1,84 & 0,87 & - & - & - & - & - & - & 1,00 & 0,15 & 0,07 & 0,14 \\
\hline magic thinking & 2,17 & 0,86 & - & - & - & - & - & - & - & 1,00 & $0,38^{\star}$ & 0,11 \\
\hline social support & 2,16 & 1,19 & - & - & - & - & - & - & - & - & 1,00 & $-0,19$ \\
\hline resignation & 1,75 & 1,27 & - & - & - & - & - & - & - & - & - & 1,00 \\
\hline
\end{tabular}


$* \mathrm{p}<.05$

Steps

Predictors

$\beta$

$\mathrm{R}^{2}$

F

Step 1

FOF

$-.39 *$

.1254

5.44

Table 3. The step-by-step ascendant regression analysis with categorization performance as the dependent variable and prospective metacognition experiences as predictor.

$* \mathrm{p}<.05$

Table 4. The one step-by-step ascendant regression analyses with categorization performance as $\underline{\text { the dependent variable and kidcope's strategies as predictors }}$

\begin{tabular}{|c|c|c|c|c|}
\hline Steps & Predictors & $\beta$ & $\mathrm{R}^{2}$ & $\mathrm{~F}$ \\
\hline Step 1 & Emotional regulation & -31 & .0668 & 3.22 \\
\hline Step 2 & Emotional regulation & $-.36^{*}$ & .1496 & 3.72 \\
\hline & magical thinking & .33 & - & - \\
\hline
\end{tabular}

$* \mathbf{p}<.05$

Table 5. The one step-by-step ascendant regression analyses with the FOF (Feeling Of Familiarity) in prospective phase as the dependent variable and coping's strategies as predictors. The best model corresponds to the step 2 


$\begin{array}{llccc}\text { Steps } & \text { Predictors } & \beta & R^{2} & F \\ \text { Step 1 } & \text { Self critism } & 0,54 & 0,2636 & 12,1 \\ \text { Step 2 } & \text { Self critism } & \mathbf{5 7 ^ { * }} & .2895 & 7,32 \\ & \text { magic thinking } & -0,22 & - & -\end{array}$

